\title{
An analysis of superplastic free forming at constant pressure
}

\author{
G. Giuliano \& S. Franchitti \\ Department of Industrial Engineering, Cassino University, Italy
}

\begin{abstract}
Superplastic materials are characterised by very low strength during forming and by large plastic deformations. Superplasticity is observed in some metal alloys when deformed under particular conditions, namely:

- very fine grain size $(10 \mu \mathrm{m})$;

- high temperature (greater than about one-half the absolute melting point);

- a controlled strain rate $\left(10^{-4}-10^{-2} \mathrm{~s}^{-1}\right)$.
\end{abstract}

In recent years, there has been a considerable interest in the aircraft and automotive industries using superplastic forming to obtain complex parts. In these industrial sectors superplastic forming (SPF) of sheet metal has been used to produce, with a low number of mechanical steps, several sheet metal components that are lighter and stronger than conventional components.

The increasing spread of superplastic forming processes has focussed the attention of technologists onto problems of optimising process parameters. The design of these processes is more difficult than conventional manufacturing operations. In fact, to successfully produce an SPF component it is essential to control a variety of different parameters during the forming process: temperature, material grain size, strain-rate distribution due to the pressure forming and the final distribution of thicknesses.

In this study the superplastic behaviour of PbSn60, an alloy that is superplastic at room temperature, is evaluated during constant pressure free bulging. A set of experimental tests were carried out in order to determine the characteristic parameters of the PbSn60.

Keywords: superplastic forming, constitutive equation, finite element method. 


\section{Introduction}

An ever-increasing number of fields in mechanical industry need to be able to produce light parts of complex shape and elevated mechanical strength. In particular, the automotive and aeronautical industries require innovatory technologies in the field of sheet metal forming processes: being able to have materials and technological processes capable of obtaining elevated plastic strain, is very attractive to designers.

A decisive innovation in the field of sheet metal forming processes, was the discovery of some metallic alloys that in given microstructural conditions of temperature and strain rate, exhibit a behaviour called superplasticity. This is characterised by an extraordinary ductility, as can be seen from percentage elongations that are one or two orders of magnitudes greater than those observed for conventional metals and alloys [1,2].

The superplastic materials of industrial interest are aluminium, titanium and magnesium-based alloys.

The need to master process parameters (particularly the pressure-time load curve) during superplastic forming requires more and more sophisticated simulation techniques. Nowadays, the finite element method represents the most common tool for planning sheet metal forming processes [3-13].

The starting point for a reliable simulation of the process is to know the characteristics of the material.

Being able to accurately model the deformation conditions is critical in superplasticity; in fact the constitutive equation, used to define the relationship in a superplastic material between the flow stress $\sigma$, the strain $\varepsilon$ and the strain rate, $\dot{\varepsilon}$, considers the effect of multiple factors, namely temperature, grain size, fraction of cavities, strain hardening/softening and strain-rate. Various researchers have proposed equations to describe the behaviour of superplastic materials using models based on three different levels: macrocospic, mesoscopic and atomic levels [14].

On the basis of the phenomenological aspects of superplastic behaviour it is possible to note a strong correlation between the flow stress and the strain rate and a weak one with the strain and the grain size:

The equation can be written as:

$$
\sigma=K \dot{\varepsilon}^{\mathrm{m}} \varepsilon^{\mathrm{n}} \mathrm{d}^{\mathrm{p}}
$$

Often the dependence of the flow stress on the grain size is neglected, and hence the constitutive equation is simplified:

$$
\sigma=\mathrm{K} \dot{\varepsilon}^{\mathrm{m}} \varepsilon^{\mathrm{n}}
$$

The method usually used to characterise superplastic material is the tensile test in which the specimen is subjected to monoaxial stress. It has been noted, however, that the free forming tests enable the characteristic parameters to be determined more reliably since the material is subject to stress conditions (biaxial stress) closer to those of the real forming process [15].

This study analyses the free forming process, at constant pressure, of $\mathrm{PbSn} 60$ an alloy that is superplastic at room temperature. It aims to verify whether eqn 
(2) is easy to implement in a computational model and whether it represents the behaviour of superplastic material to a good degree of accuracy.

\section{Experimental work}

The constant pressure free forming experiments were performed using the equipment designed by the authors and shown in Figure 1 [16].

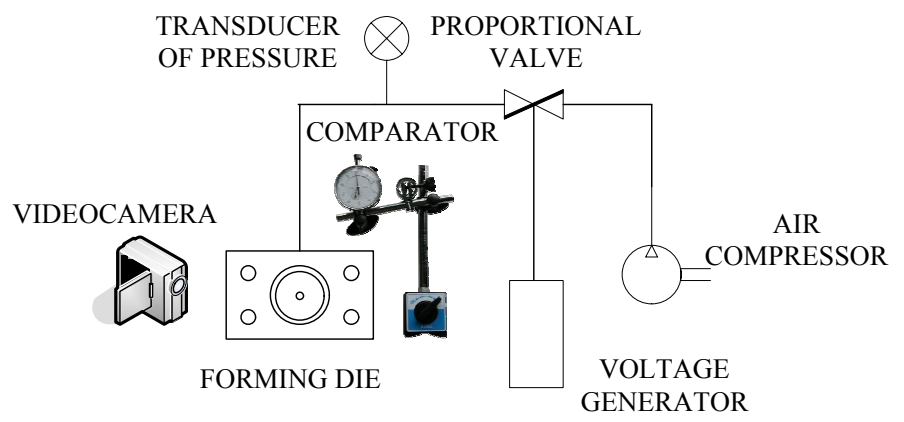

Figure 1: The equipment used to carry out the experimental tests.

It comprises a compressor that sends pressurised air to a proportional valve whose function is to regulate the pressure within the circuit; a pressure transducer; and an open die that includes the upper and lower parts, both of which made of steel. The upper plate measures 180x100x100 mm and it has a $60 \mathrm{~mm}$ diameter central hole of through which the sheet is formed and four holes for linking it up to the lower plate. The latter is of similar dimensions to the former and has a central hole too to allow the compressed air to be fed through (figure 2).

The material used for SPF was $0.3 \mathrm{~mm}$ thick $\mathrm{Pb} / \mathrm{Sn}$ alloy composed of (in wt. $\%) 60 \% \mathrm{~Pb}$ and $40 \% \mathrm{Sn}$ (non eutectic composition). This material displays superplastic characteristics at room temperature and it therefore does not require the use of a furnace and expensive apparatus. The superplastic PbSn60 alloy has mechanical properties that are too poor to be used to produce real industrial components, but it proves to be advantageous for laboratory activity. This material is commercially available in the form of PbSn60 welding bars; in order to drastically reduce grain size, and therefore to respect one of the conditions necessary for exhibiting superplastic behaviour, it is subjected to bending and rolling cycles [16].

Two series of tests were carried out: the first at a forming pressure of $0.10 \mathrm{MPa}$ and the second at a pressure of $0.18 \mathrm{MPa}$. For each single pressure value 5 tests were carried out for a total of 10 tests, and the time step taken for the sheet to pass through the normalized height $\mathrm{H}=0$ to $\mathrm{H}=1$ was measured for each single test. The normalized height is defined as $\mathrm{H}=\mathrm{h} / \mathrm{a}$, where $\mathrm{h}$ is the polar dome height and $\mathrm{a}$ is the die radius. 


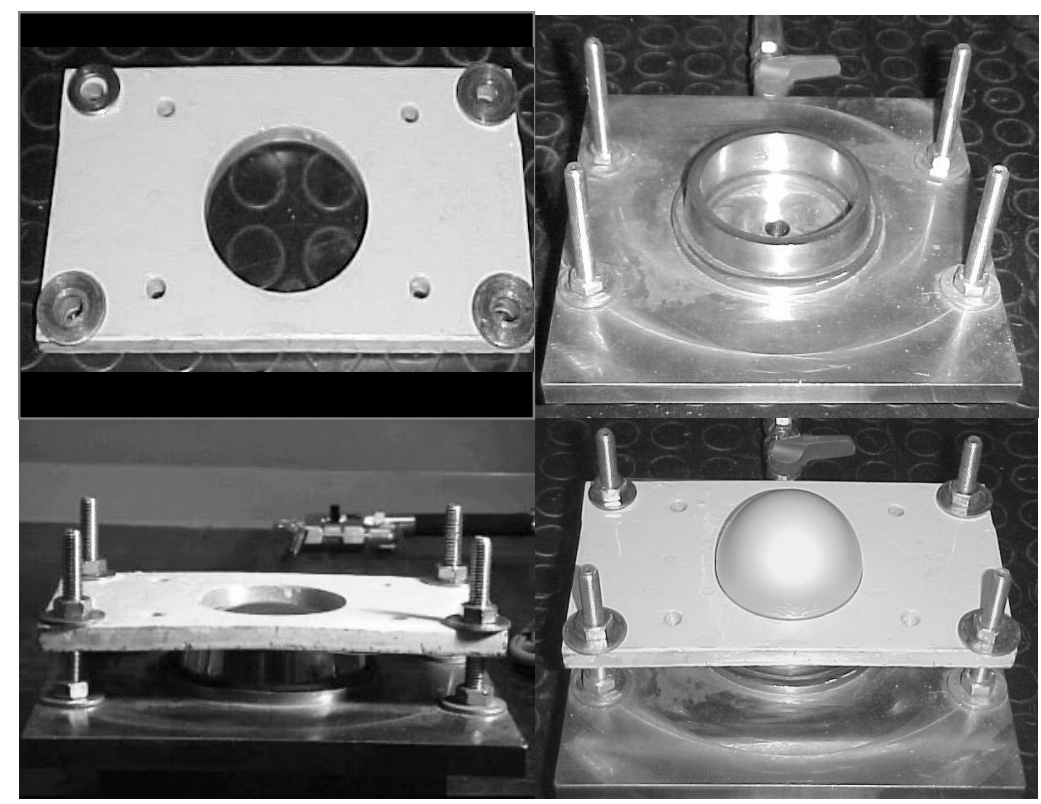

Figure 2: $\quad$ Shape of the die.

Since it was not possible by means of an analogic comparator to memorize the heights reached by the sheet, the trend of height versus time was obtained using a video camera. The videos of the forming test were uploaded to a PC by means of an image acquisition system, thereby enabling the data to be read.

Figure 3 shows the results obtained.

The bars showing the mean standard deviation are highlighted. The results obtained were analysed using the Grubbs test to check for the presence or not of anomalous values. The tests predict that for each value of $\mathrm{H}$, a shift in the time measured compared to the mean value is determined. The measured shift in relation to the standard deviation of the population under examination is compared to a critical value linked to the distribution of the measured data.

The constant of the material $\mathrm{m}$ was determined as shown by various authors [17], by means of the expression:

$$
\mathrm{m}=\frac{\ln \left(\mathrm{p}_{2} / \mathrm{p}_{1}\right)}{\ln \left(\mathrm{t}_{1} / \mathrm{t}_{2}\right)}
$$

where, in this paper, $t_{1}$ and $t_{2}$ are the forming time values necessary to produce the same dome geometry (that is the same value of $\mathrm{H}$ ) at constant pressures $\mathrm{p}_{1}$ and $\mathrm{p}_{2}$, respectively. Table 1 summarizes the $\mathrm{m}$ values measured during the forming process.

Figure 4 shows how this parameter is dependent on the deformation obtained (H). In particular it proves to decrease slightly during deformation. A means value of $\mathrm{m}$ between $\mathrm{H}=0.2$ and $\mathrm{H}=1$ will be considered for the numerical analysis. 

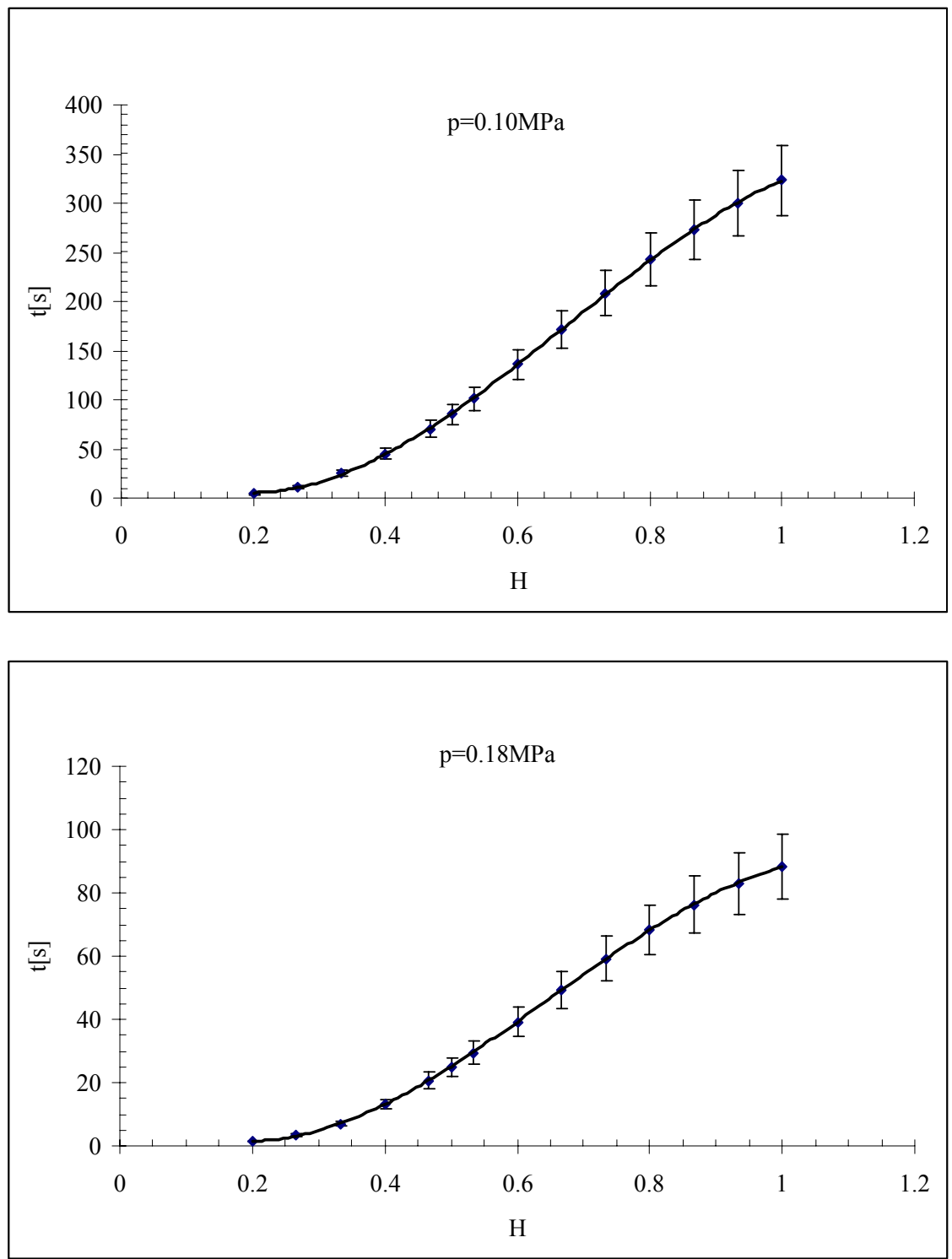

Figure 3: Experimental results.

\section{Numerical analysis}

Using commercial finite element software, a constant pressure free bulging process of the superplastic PbSn60 alloy was simulated. The element type used in the analysis is a four-node, isoparametric, arbitrary quadrilateral written for axisymmetric applications [18]. Due to the symmetry of the geometry, load and 
constraint conditions, only half of the cross-section of the sheet metal was analysed. Moreover, it was necessary to impose constraint conditions on the periphery of the sheet, in order to simulate the action of a blank holder. The die has a circular geometry with an aperture diameter of $60.0 \mathrm{~mm}$ and a die entry radius of $2.0 \mathrm{~mm}$. Rigid-plastic flow formulation was applied to the superplastic forming analysis [19].

Table 1: $\quad$ Experimental values of the strain-rate sensitivity index.

\begin{tabular}{|c|c|}
\hline $\mathrm{H}$ & $\mathrm{m}$ \\
\hline 0.200 & 0.467 \\
\hline 0.267 & 0.482 \\
\hline 0.333 & 0.481 \\
\hline 0.400 & 0.478 \\
\hline 0.467 & 0.476 \\
\hline 0.500 & 0.473 \\
\hline 0.533 & 0.470 \\
\hline 0.600 & 0.468 \\
\hline 0.667 & 0.465 \\
\hline 0.733 & 0.462 \\
\hline 0.800 & 0.458 \\
\hline 0.867 & 0.454 \\
\hline 0.933 & 0.449 \\
\hline 1.000 & 0.467 \\
\hline
\end{tabular}

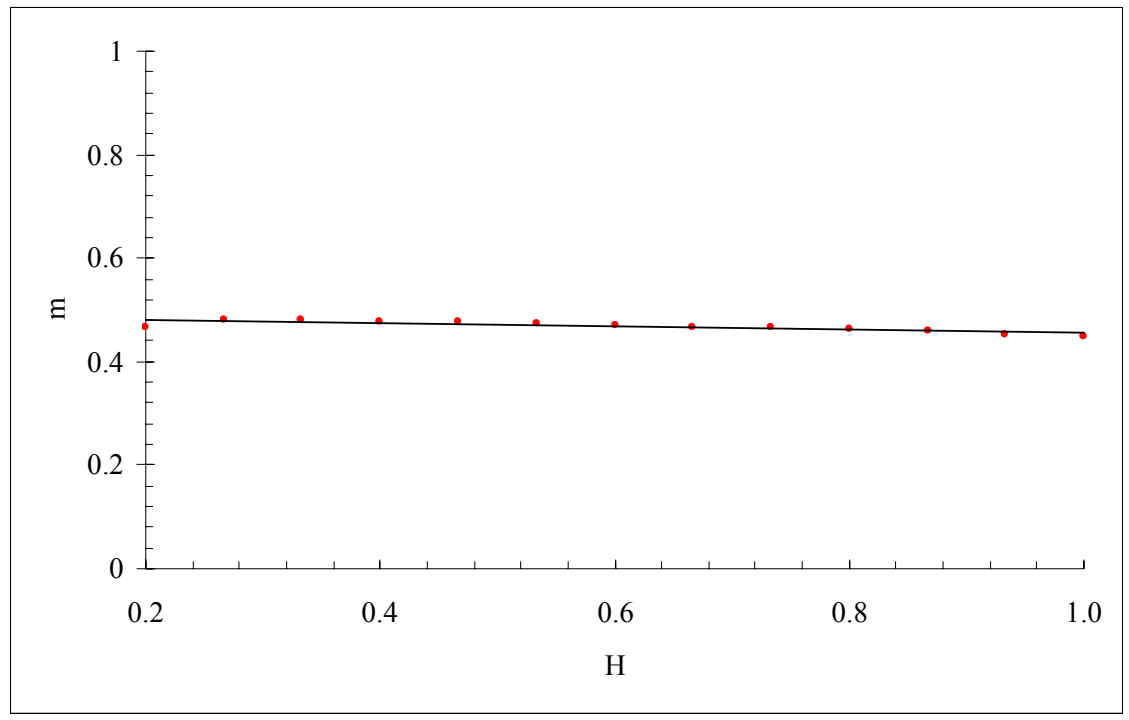

Figure 4: $\quad$ Experimental trend of $m$ value. 

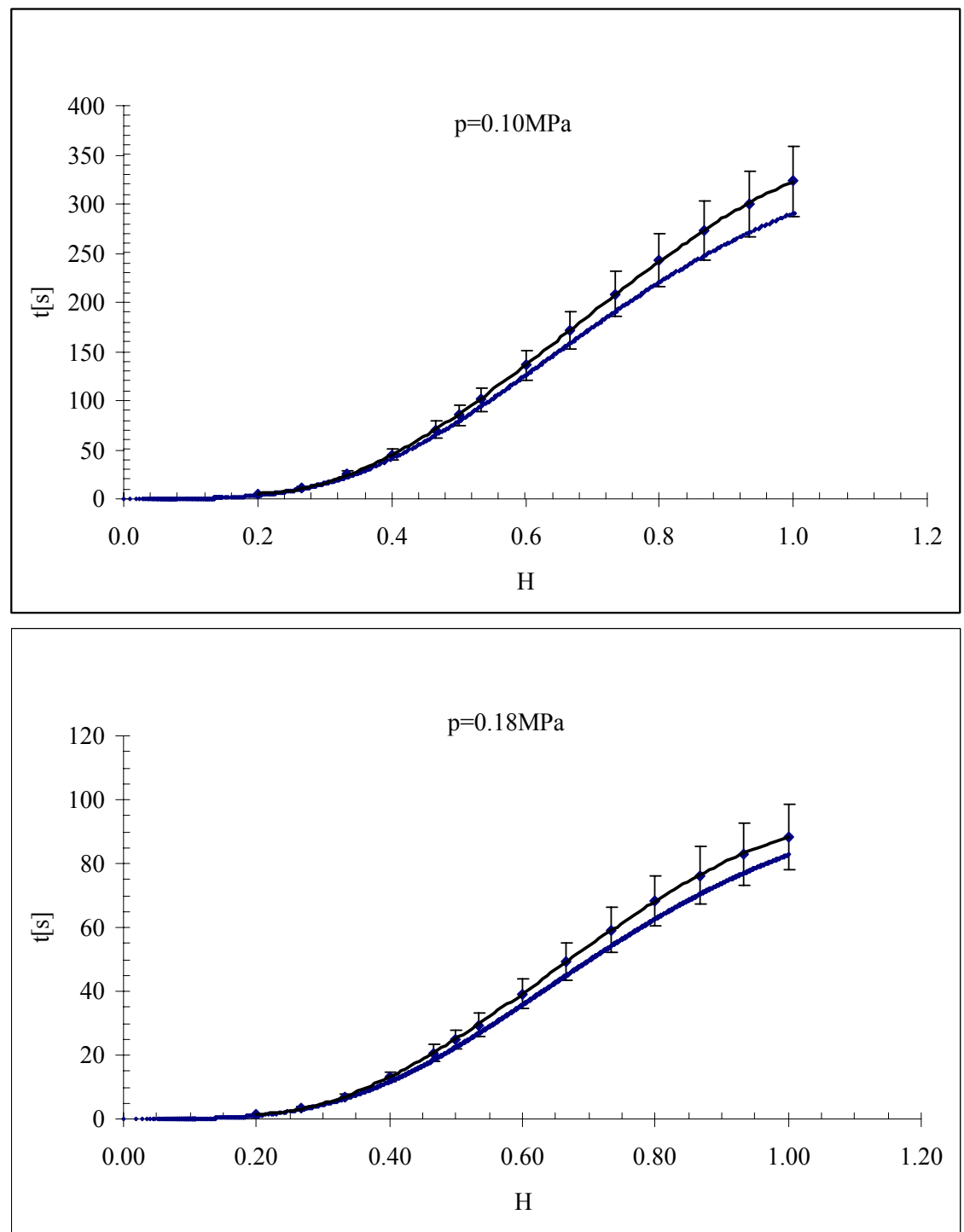

Figure 5: Comparison between the numerical and experimental results.

The constants of the material, introduced in the code, for the process simulation, were determined starting from an original characterisation methodology proposed by authors in [17].

The material constants were determined as:

$\mathrm{m}=0.468$

$\mathrm{n}=-0.029$

$\mathrm{K}=146.515 \mathrm{MPa}^{*} \mathrm{~s}$ 
From the results of the numerical analysis it is possible to plot the trend of time versus the normalized polar height $\mathrm{H}$. It can be seen that this curve lies between the bars of the standard deviation of the mean experimentally obtained results (figure 5).

\section{Conclusions}

This study analysed the behaviour of the superplastic Pb-Sn60 alloy as it underwent a superplastic free forming process at a constant pressure. A comparison between the experimental results and the ones from a numerical analysis of the forming process justifies the approximation introduced to determine the constant $\mathrm{m}$. In fact to consider a simplified constitutive equation (eq.2), the numerical analysis uses a mean value of $\mathrm{m}$ in relation to the deformation $(\mathrm{H})$.

\section{References}

[1] Hamilton C.H. and Ghosh A.K., Superplastic sheet forming, Metals Handbook, 1988.

[2] Pilling J. and Ridley N., Superplasticity in Crystalline Solids, The Institute of Metals, London, 1989.

[3] Sadeghi R. and Pursell Z., Finite element modeling of superplastic forming with precise dies, Superplasticity and Superplastic Forming, The Minerals, Metals \& Materials Society, Warrendale, 1995.

[4] Chandra N., 1988, Analysis of superplastic metal forming by a finite element method, International Journal for Numerical Methods in Engineering, vol. 26, pp. 1925-1944.

[5] Chandra N. and Rama S.C., 1992, Application of finite element method to the design of superplastic forming processes, Journal of Engineering for Industry, vol. 114, pp. 452-458.

[6] Bonet J., Bhargava P. and Wood R.D., 1997, Finite element analysis of the superplastic forming of thick sheet using the incremental flow formulation, International Journal for Numerical Methods in Engineering, vol. 40, n 17 , pp. 3205-3228.

[7] Bellet M., Massoni E. and Chenot J.L., 1987, A viscoplastic membrane formulation for the 3-D analysis of superplastic forming of thin sheet, Proceedings of the International Conference on Computational Plasticity, pp. 917-926.

[8] Huh H., Han S.S., Lee J.S. and Hong S.S., 1995, Experimental verification of superplastic sheet-metal forming analysis by the finiteelement method, Journal of Materials Processing Technology, vol. 49, pp. 355-369.

[9] Kim Yong H., Hong S.S., Lee J.S. and Wagoner R.H., 1996, Analysis of superplastic forming processes using a finite-element method, Journal of Materials Processing Technology vol. 62, pp. 90-99. 
[10] Xing H.L. and Wang Z.R., 1997, Finite-element analysis and design of thin sheet superplastic forming, Journal of Materials Processing Technology, vol. 68, pp. 1-7.

[11] Doltsinis J. St., Loginsland J. and Nolting S., 1987, Some developments in the numerical simulation of metal forming processes, Proceedings of the International Conference on Computational Plasticity, Barcelona.

[12] Carrino L., Giuliano G. and Napolitano G., 2003, A posteriori optimisation of the forming pressure in superplastic forming processes by the finite element method, Finite Elements in Analysis and Design, vol. 39, n 11, pp. 1083-1093.

[13] Carrino L., Giuliano G. and Palmieri C., 2003, On the optimization of superplastic forming processes by the finite element method, Journal of Materials Processing Technology, vol. 143-144, pp. 373-377.

[14] Chandra N., 2002, Constitutive behavior of superplastic materials, International Journal of Non-Linear Mechanics, vol. 37, pp. 461-484.

[15] Carrino L., Giuliano G. and Polini W., 2003, A method to characterise superplastic materials in comparison with alternative methods, Journal of Materials Processing Technology, vol. 138, pp. 417-422.

[16] Carrino L. and Giuliano G., 1999, Finite element modelling and the experimental verification of superplastic forming, Advanced Performance Materials, vol. 6, n 2, pp. 159-169.

[17] Giuliano G. and Franchitti S., 2006, On the Evaluation of Superplastic Characteristics using the Finite Element Method, International Journal of Machine Tools and Manufacture, vol. 47, pp. 471-476.

[18] MSC. Marc 2005 Vol. B, Element library.

[19] Zienkiewicz O.C., Flow formulation for numerical solution of forming processes, Numerical Analysis of Forming Processes, Wiley, New York, 1984. 